\title{
Plant Growth Promoting Rhizobacteria (PGPRs) Alter Plant Host Somatic Mutation Frequencies
}

\author{
Aparna C., Pallavi S. Nair, Jasmine M. Shah*
}

DOI: 10.18811/ijpen.v5i03.2

\begin{abstract}
Plant growth promoting rhizobacteria (PGPRs) are a group of soil bacteria which can induce positive growth in plants by different mechanisms. This work intends to find the effect of PGPRs on two classes of somatic mutations in the host, frame shift mutation (FSM) and somatic homologous recombination (SHR) and, compare the same with that of a pathogen. Somatic mutations in plants are important as they are an adaptation strategy to overcome stressful conditions and also get passed on to the next generations. The mutation detector Arabidopsis thaliana lines carrying a non-functional $\beta$-glucuronidase gene (GUS) were used to score the mutation events. One day-old mutant seedlings were co-cultivated with the PGPRs (Rhizobium leguminosarum and Pseudomonas fluorescens) and the pathogenic strain (P. syringae) for two different post-infection durations ( $4 \mathrm{~h}$ and $48 \mathrm{~h}$ ). A reversion of the mutated GUS to its functional form resulted in blue spots in the host plant. Based on the number of blue spots seen, the mutation frequencies were estimated. An increase in FSM was observed in plants co-cultivated with $R$. leguminosarum for 4 $\mathrm{h}$ as well as $48 \mathrm{~h}$. $R$. leguminosarum suppressed SHR frequency $4 \mathrm{~h}$-post infection, which significantly increased at $48 \mathrm{~h}$. In contrast, $P$. fluorescens infection lead to a temporal suppression of FSM and induction of SHR at $4 \mathrm{~h}$. Subsequently, the SHR rates reduced significantly, i.e. lower than the uninfected controls at $48 \mathrm{~h}$. The pathogenic strain P. syringae temporally increased FSM in plants and also enhanced SHR rates in plants $4 \mathrm{~h}$ post-infection, which also subsequently reduced $48 \mathrm{~h}$ post infection. To the best of our knowledge, there are no other reports comparing the effect of PGPRs on host somatic mutation rates.
\end{abstract}

Key words: Arabidopsis, Frame-shift mutation, Host somatic mutation frequencies, Plant growth promoting rhizobacteria (PGPR), Somatic homologous recombination.

International Journal of Plant and Environment (2019)

\section{INTRODUCTION}

Dlants, being sedentary in lifestyle, often have to face extremities of various abiotic and biotic factors leading to stressful conditions. As a result, several mechanisms have been developed which allow them to cope up with various stresses (Hauser et al., 2011; Kranner et al., 2010; Tuba and Lichtenthaler, 2007). Genomic instability that results in flexibility is one among such adaptation strategies. Somatic mutation events are a major cause of this genome instability (Puchta et al., 1994). In case of plants, somatic mutations are of great importance as plants do not have a predetermined germline and the reproductive structures are derived from somatic cells in due course of their development (Kovalchuk et al., 2000). Such mutations include frame-shift mutation (FSM) , point mutation and somatic homologous recombination (SHR).

Studies have already been done on the effect of different stresses on the somatic mutation frequency. Different abiotic stresses have been known to show heritable alterations in the frequency of all three major kinds of somatic mutations (Rahavi et al., 2011). Previous studies on the effect of biotic stress using some plant pathogens resulted in high rates of recombination, transposition and double strand breaks (Kathiria et al., 2010) while different strains of Agrobacterium tumefaciens resulted in suppression of various classes of somatic mutations (Shah et al., 2015).

This study is oriented to check the rates of somatic mutation frequency when plants are infected by two plant growth promoting rhizobacteria (PGPRs), Rhizobium leguminosarum, a close relative of Agrobacterium and, Pseudomonas fluorescens, which are widely used biocontrol agents. PGPRs are a group of bacteria which can induce a positive growth in plants by both direct and indirect means like nitrogen fixation, solubilisation of nutrients, production of growth regulators, competitive exclusion of pathogens or removal of phytotoxic substances, stimulation of mycorrhizal development etc. (Lugtenberg and Kamilova, 2009; Bashan and de-Bashan, 2010). Mutation frequency was determined for another set of plants also
Department of Plant Science, Central University of Kerala, Kasaragod-671316, Kerala, INDIA

Corresponding author: Dr. Jasmine M. Shah, Department of Plant Science, Central University of Kerala, Kasaragod-671316, Kerala, INDIA, Mobile: +91-8281409309, Email: jasmine@cukerala.ac.in

How to cite this article: Aparna C., Nair, P.S. and Shah J.M. (2019). Plant Growth Promoting Rhizobacteria (PGPRs) Alter Plant Host Somatic Mutation Frequencies. International Journal of Plant and Environment 5(3): 149-154.

Source of support: Nil

Conflict of interest: None

Submitted:12.06.2019 Accepted:01.07.2019 Published:31.07.2019

that were infected with $P$. syringae, a known plant pathogen to compare the effects with.

We analysed the frequencies of two different classes of somatic mutations-SHR and FSM in this study. SHR is the intra-chromosomal recombination that occurs in somatic cells. FSM are characterised by insertion or deletion of nucleotides resulting in a shift in the reading frame. Mutation frequency rates were scored using Arabidopsis mutation detector line plants that harbour mutated GUS construct that is capable of revealing mutation frequency during GUS histochemical staining due to reversion of mutations. The line R2L1 was used in scoring SHR frequency while the line G10 was used to score FSM rates. Arabidopsis seedlings were co-cultivated with the bacteria for two time intervals, 4hours and 48 hours to study the dynamics of mutations.

\section{Materials and Methods}

\section{Arabidopsis mutation detector lines}

Line $\mathrm{G} 10$ having a microsatellite insertion (stretch of $10 \mathrm{Gs}$ ) within the GUS ORF was used to score FSMs (Fig. 1A). SHRs were scored 
using line R2L1, where the recombination substrates are inverted repeats of a truncated GUS gene (Fig. 1B). The line G10 (Columbia ecotype) as well as the line R2L1 (Columbia ecotype) were obtained from Francois Belzile (University of Laval, Canada).

\section{Bacterial strains}

The bacterial strains Rhizobium leguminosarum (Col. No. 99) and two species of Pseudomonas were used for infection in this work, P. fluorescens (Col. No. 103) and P. syringae (Col. No. 1604) were got from The Microbial Type Culture Collection and Gene Bank (MTCC), Chandigarh. R. leguminosarum was grown on yeast-mannitol agar (YMA) media while the Pseudomonas strains were grown on nutrient agar (NA) media. Before infection suspension cultures were made by inoculating single colonies of bacteria into respective liquid media [yeast-mannitol broth (YMB) and nutrient broth (NB)].

\section{Mode of infection and plant growth}

Arabidopsis seeds were surface sterilised with $500 \mu \mathrm{l}$ of $70 \%$ ethanol and rinsed well with sterile water. These seeds were further washed with $0.5 \%$ sodium hypochlorite and finally rinsed with sterile water for 4-5 times. Sterilized seeds were plated on germination media (MS media with 3\% sucrose and 1\% agar, pH 5.6) in $35 \mathrm{~mm}$ sterile culture plates, maintaining uniform spacing between the seeds. Plates containing seeds were kept for vernalisation at $4^{\circ} \mathrm{C}$ for 48 hours. After two days plates were moved to growth chamber (Percival) having uniform light intensity of 8000 lux units under a 16 -h light/8-h dark cycle, maintaining $22^{\circ} \mathrm{C}$ and $80 \%$ humidity. The infection was carried out by pouring on the bacterial suspension cultures onto the one day-old seedlings and subjecting it to vacuum infiltration for five minutes. Plants treated with liquid media devoid of bacteria were taken as the control for the experiment. After respective co-cultivation period, the plants were washed in liquid MS media containing $3 \%$ sucrose, $0.05 \%$ plant preservation mixture (PPM) and cefotaxime ( $\left.250 \mathrm{mg} \mathrm{L}^{-1}\right)$. The infected seedlings were then gently dropped onto the germination media, MS media along with sucrose and agar, $\mathrm{pH} 5.6$, supplemented with PPM (0.05\%) and cefotaxime ( $\left.250 \mathrm{mg} \mathrm{L}^{-1}\right)$ in $90 \mathrm{~mm}$ sterile culture plates maintaining equal distance using a wide mouthed pipette and kept back in the growth chamber.
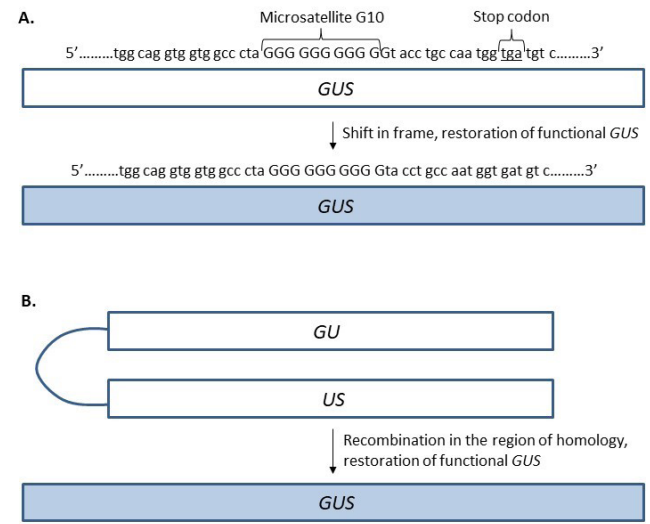

Fig. 1: A. The GUS gene construct with an insertion of a microsatellite region of $10 \mathrm{Gs}$ to detect frame-shift mutations (Azaiez et al., 2006; Shah et al., 2015), B. Inverted repeat of the truncated GUS gene segments that restore function after homologous recombination (Puchta et al., 1994; Shah et al., 2015).

\section{$\beta$-Glucuronidase (GUS) histochemical staining}

Three week-old infected plants were taken as explants and GUS histochemical staining was done in multi-well plates according to Jefferson's protocol (Jefferson, 1989). The explants were initially incubated at $37^{\circ} \mathrm{C}$ for one hour in $50 \mathrm{mM}$ sodium phosphate buffer ( $\mathrm{pH} 7.0)$ containing $1 \%$ Triton X-100. The explants were then put in $1 \mathrm{mM}$ X-Gluc (5-bromo-4-chloro-3-indolylglucuronide) staining solution and subjected to vacuum infiltration for five minutes and incubation at $37^{\circ} \mathrm{C}$ for 24 hours. These plants were then bleached with $70 \%$ ethanol. The blue spots as a result of reversion of mutations were observed under a stereomicroscope (Carl Zeiss) (Fig. 2).

\section{Mutation frequency scoring and statistical analysis}

The experiments were done in triplicates, each treatment involving around 100 plants. The mutation frequencies were calculated as the average of the number of blue spots seen on the plants. The mutation frequencies of infected plants were compared with that of the respective control plants. The statistical significance of experiments was confirmed by performing Student's t test and One-way Analysis of Variance (ANOVA). Significant difference was observed in all the cases at $5 \%$ level and graphs were plotted accordingly. Statistical analyses were performed using MS OfficeExcel, Tukey Honestly Significant Difference test and Statistical Package for the Social Sciences (SPSS) software.

\section{Results and Discussion}

Previous work done by different researchers has revealed about the influence of different stress-causing agents on plant somatic mutations including FSM and SHR. Abiotic stresses like short wavelength radiation (UV-C) and salt were found to increase the rates of SHR (Hohn et al., 2006; Kovalchuk et al., 2006) while heat and flood increased point mutation frequencies (Yao and Kovalchuk, 2011). Biotic agents like Escherichia coli and Peronospora parasitica, a pathogen, were capable of inducing transversion and SHR, respectively (Shah et al., 2015; Lucht et al., 2002). The influence of

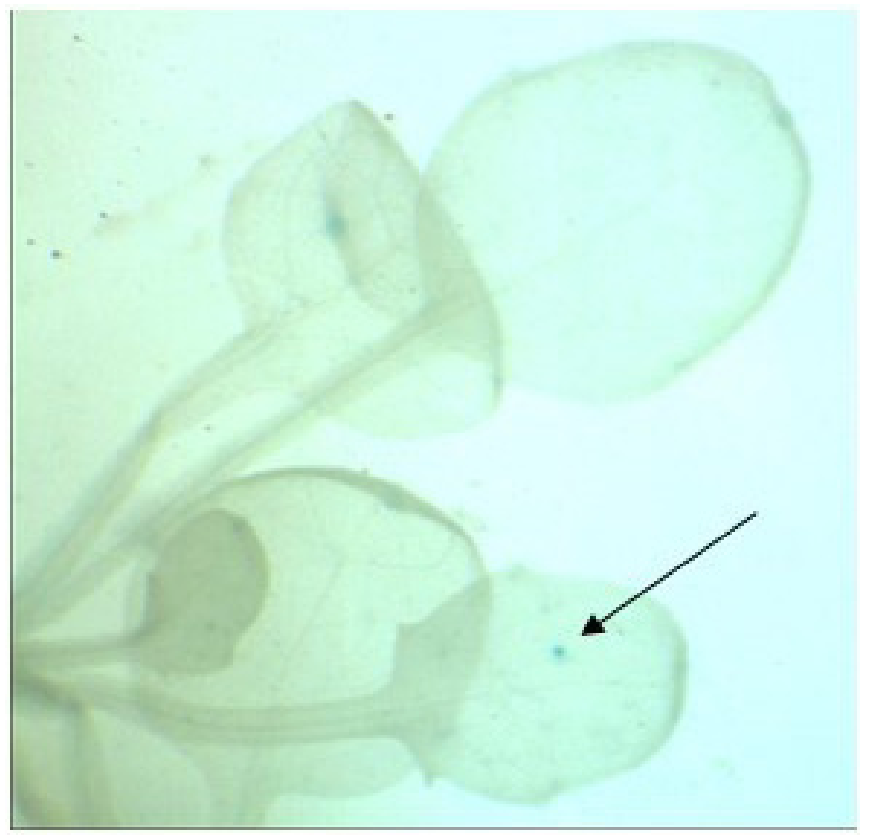

Fig. 2: Blue colour spot (arrow) appeared as a result of reversion of mutated GUS gene. 
two PGPRs and pathogen on somatic mutations are reported in this work.

\section{FSM induced by $R$. leguminosarum and $P$. syringae and suppressed by $P$. fluorescens}

To score the FSM rates, Arabidopsis mutation detector line G10 was used. The line $\mathrm{G} 10$ has an insertion of $10 \mathrm{Gs}$ in the microsatellite region within the GUS gene altering the reading frame by bringing a stop codon and making the GUS gene inactive (Fig. 1A). A deletion or addition in the microsatellite region during DNA replication can eliminate the stop codon and make the GUS gene functional. One day-old seedlings were co-cultivated with $R$. leguminosarum, $P$. fluorescens and $P$. syringae separately for 4 and 48 hours. The blue spots on GUS stained plants were counted and analysed statistically in order to score the mutation frequency (Table 1).

Upon infection with $R$. leguminosarum, the number of blue spots that indicate the reversion of mutation were found to be greater than that on the control plants which were treated with YMB devoid of any bacteria in both time intervals (Fig. 3A, B). The duration of co-cultivation seemed to have no evident effect on the reversion rate (Fig. $3 \mathrm{C}$ ). In the case of infection with $P$. syringae, an induction of FSM was observed (Fig. 4A, B). The rate of FSM enhanced as the co-cultivation period increased from 4 hours to 48 hours (Fig. 4C). Unlike the cases of both $R$. leguminosarum and $P$. syringae, an obvious suppression of FSM was seen due to infection with $P$. fluorescens in both 4 hours and 48 hours of co-cultivation
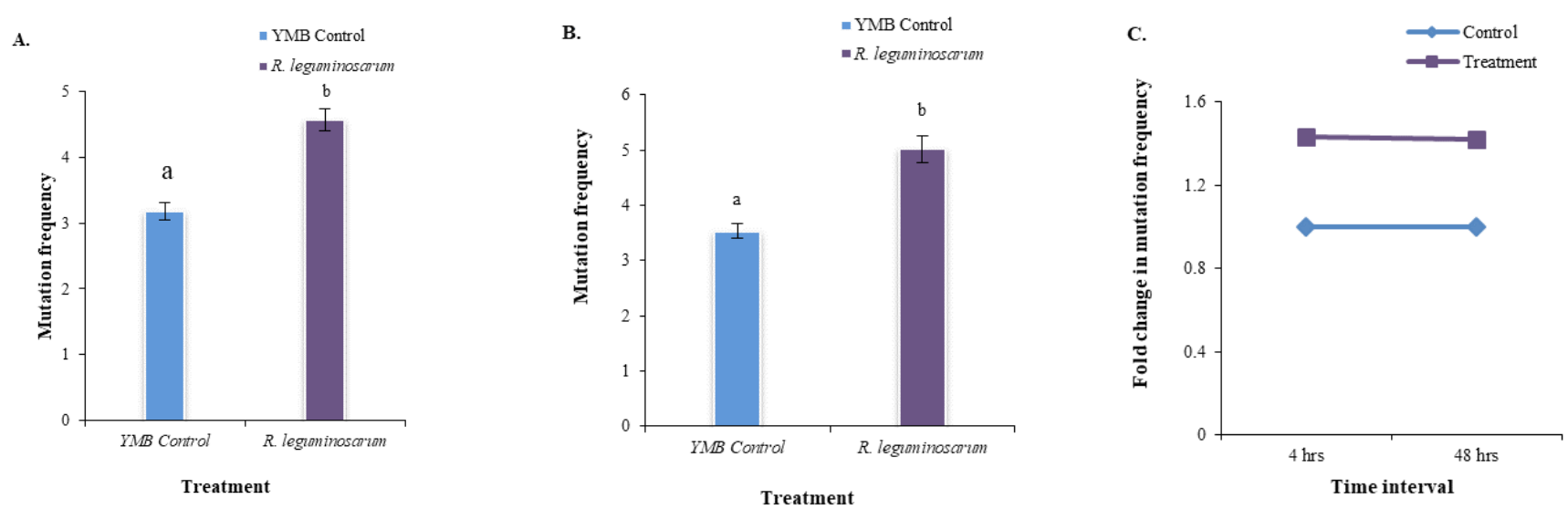

Fig. 3: A. Effect of R. leguminosarum on FSM in control (treated with yeast mannitol broth devoid of bacteria) and infected plants at 4 hours, B. Effect of $R$. leguminosarum on FSM in control and infected plants at 48 hours, $\mathbf{C}$. Temporal influence of $R$. leguminosarum on host FSM rates. Bars indicate the standard error of the mean of three biological repeats, each consisting of around 100 plants. ${ }^{\mathrm{a}, \mathrm{b}}$ represent that different letters stand for significant difference at $\mathrm{P}<5 \%$ level as determined by Student's t-test.
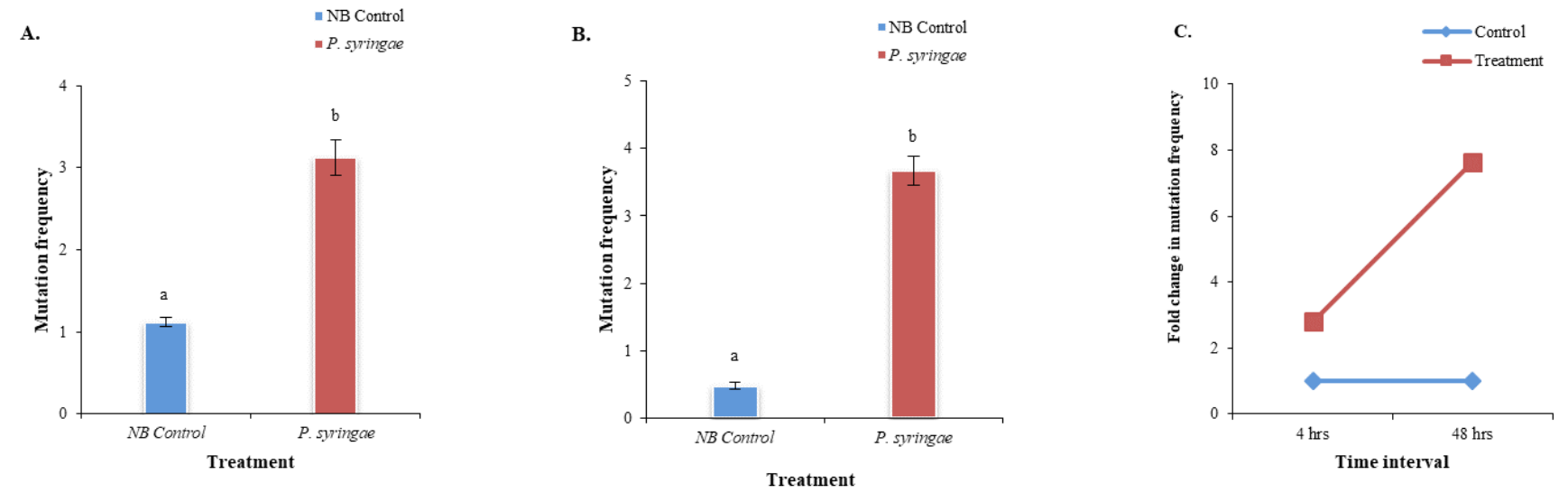

Fig. 4: A. Effect of $P$. syringae on FSM in control (treated with nutrient broth devoid of bacteria) and infected plants at 4 hours, B. Effect of $P$. syringae on FSM in control and infected plants at 48 hours, $\mathbf{C}$. Temporal influence of $P$. syringae on host FSM rates. Bars indicate the standard error of the mean of three biological repeats, each consisting of around 100 plants. ${ }^{a, b}$ represent that different letters stand for significant difference at $\mathrm{P}<5 \%$ level as determined by Student's t-test.

Table 1: Total number of events and data observed in frame-shift mutation.

\begin{tabular}{|c|c|c|c|c|c|c|c|c|c|c|}
\hline \multirow{2}{*}{$\frac{\text { Treatment }}{\text { Time interval }}$} & \multicolumn{2}{|c|}{$\begin{array}{l}\text { Control (yeast- } \\
\text { mannitol broth) }\end{array}$} & \multicolumn{2}{|c|}{$\begin{array}{l}\text { Rhizobium } \\
\text { leguminosarum }\end{array}$} & \multicolumn{2}{|c|}{$\begin{array}{l}\text { Control (nutrient } \\
\text { broth) }\end{array}$} & \multicolumn{2}{|c|}{$\begin{array}{l}\text { Pseudomonas } \\
\text { fluorescens }\end{array}$} & \multicolumn{2}{|c|}{$\begin{array}{l}\text { Pseudomonas } \\
\text { syringae }\end{array}$} \\
\hline & $4 \mathrm{~h}$ & $48 \mathrm{~h}$ & $4 \mathrm{~h}$ & $48 \mathrm{~h}$ & $4 \mathrm{~h}$ & $48 \mathrm{~h}$ & $4 \mathrm{~h}$ & $48 \mathrm{~h}$ & $4 \mathrm{~h}$ & $48 \mathrm{~h}$ \\
\hline Total number of plants taken & 451 & 351 & 454 & 385 & 397 & 358 & 563 & 327 & 347 & 301 \\
\hline Total number of blue spots observed & 1435 & 1239 & 2071 & 1930 & 443 & 172 & 550 & 51 & 1085 & 1106 \\
\hline Average number of spots observed & 3.182 & 3.53 & 4.562 & 5.013 & 1.116 & 0.480 & 0.977 & 0.156 & 3.127 & 3.674 \\
\hline Standard error of the mean & 0.131 & 0.132 & 0.166 & 0.249 & 0.059 & 0.047 & 0.035 & 0.043 & 0.212 & 0.212 \\
\hline
\end{tabular}


(Fig. 5A, B). A trend of increased suppression rate, about 2.7 times, was noticeable (Fig. 5C).

\section{Co-cultivation with $R$. leguminosarum shows increased SHR rates while $P$. fluorescens and $P$. syringae show decreased SHR rates}

The line R2L1 having the GUS gene interrupted by two inverted catalase introns (589 bp) was used to score SHR events (Fig. 1B). A recombination between the homologous regions restores the functional GUS gene that gets expressed as blue colour. Here also the experiment was done on one day-old seedlings for 4 and 48 hour time durations. The plants were infected with the three bacterial strains as mentioned earlier while the control plants were treated with the respective liquid media devoid of bacteria.
The number of blue spots that appeared on the plants was lower than that on the controls indicating a suppression of SHR rates during the initial 4 hours post infection by R. leguminosarum (Fig. 6A, Table 2). Interestingly, the rates subsequently enhanced and went above the rates of control plants as the co-cultivation period was extended upto 48 hours (Fig. 6B, C). Quite opposite to the results of $R$. leguminosarum, an initial enhancement in the frequency of SHR was observed in the case of 4 hours post-infection by $P$. fluorescens (Fig. 7A) while the rates of SHR came down even below that of the control plants as the time period of co-cultivation was extended upto 48 hours (Fig. 7B, C). P. syringae infection lead to enhanced SHR rates during both the infection periods (Fig. 8A, B). A fold change of approximately 3.4 times was seen in case of SHR reduction rate as the duration of co-cultivation increased from 4 hours to 48 hours (Fig. 8C).
A.

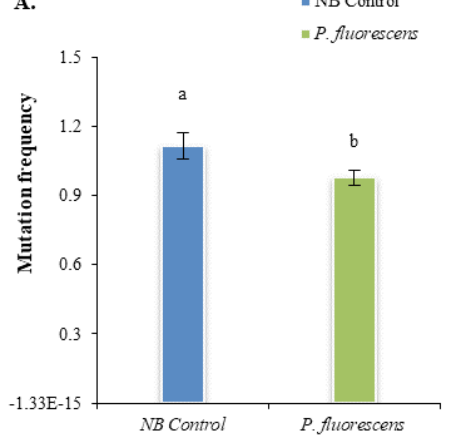

Treatment
B.

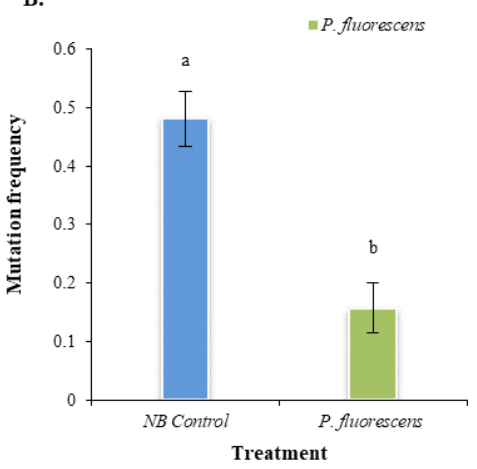

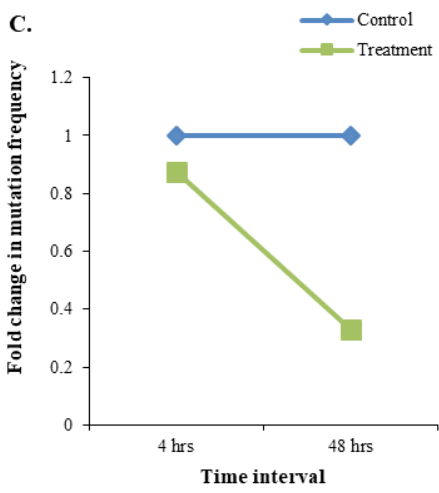

Fig. 5: A. Effect of $P$. fluorescens on FSM in control (treated with nutrient broth devoid of bacteria) and infected plants at 4 hours, B. Effect of $P$. fluorescens on FSM in control and infected plants at 48 hours, $\mathbf{C}$. Temporal influence of $P$. fluorescence on host FSM rates. Bars indicate the standard error of the mean of three biological repeats, each consisting of around 100 plants. ${ }^{a, b}$ represent that different letters stand for significant difference at $\mathrm{P}<5 \%$ level as determined by Student's t-test.
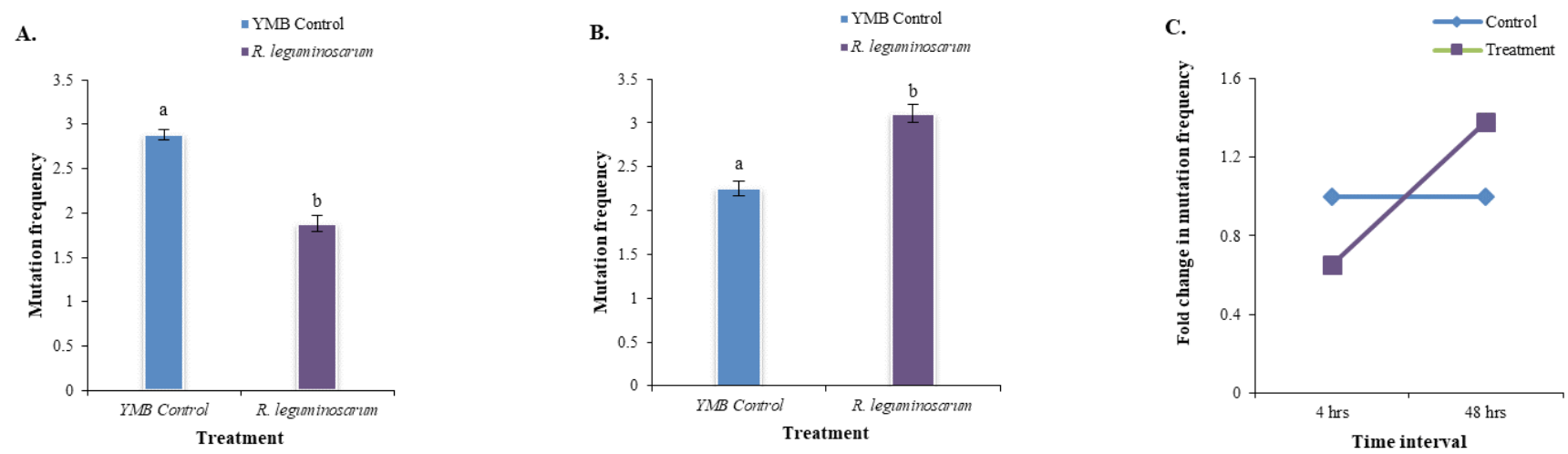

Fig. 6: A. Effect of R. leguminosarum on SHR in control (treated with yeast mannitol broth devoid of bacteria) and infected plants at 4 hours, B. Effect of R. leguminosarum on SHR in control and infected plants at 48 hours, $\mathbf{C}$. Temporal influence of $R$. leguminosarum on host SHR rates. Bars indicate the standard error of the mean of three biological repeats, each consisting of around 100 plants. ${ }^{a, b}$ represent that different letters stand for significant difference at $5 \%$ level as determined by Student's t-test.

Table 2: Total number of events and data observed in somatic homologous recombination.

\begin{tabular}{llllllllccccc}
\hline & \multicolumn{2}{l}{$\begin{array}{l}\text { Control (yeast- } \\
\text { mannitol broth) }\end{array}$} & $\begin{array}{l}\text { Rhizobium } \\
\text { leguminosarum }\end{array}$ & \multicolumn{2}{l}{$\begin{array}{l}\text { Control (nutrient } \\
\text { broth) }\end{array}$} & $\begin{array}{l}\text { Pseudomonas } \\
\text { fluorescens }\end{array}$ & $\begin{array}{l}\text { Pseudomonas } \\
\text { syringae }\end{array}$ \\
\hline Time interval & $4 \mathrm{~h}$ & $48 \mathrm{~h}$ & $4 \mathrm{~h}$ & $48 \mathrm{~h}$ & $4 \mathrm{~h}$ & $48 \mathrm{~h}$ & $4 \mathrm{~h}$ & $48 \mathrm{~h}$ & $4 \mathrm{~h}$ & $48 \mathrm{~h}$ \\
Total number of plants taken & 748 & 538 & 437 & 429 & 378 & 363 & 561 & 367 & 417 & 641 \\
Total number of blue spots observed & 2155 & 1213 & 821 & 1333 & 215 & 312 & 3319 & 273 & 1370 & 940 \\
Average number of spots observed & 2.881 & 2.255 & 1.879 & 3.107 & 0.569 & 0.86 & 5.916 & 0.75 & 3.309 & 1.466 \\
Standard error of the mean & 0.062 & 0.086 & 0.09 & 0.101 & 0.034 & 0.045 & 0.166 & 0.029 & 0.15 & 0.053 \\
\hline
\end{tabular}



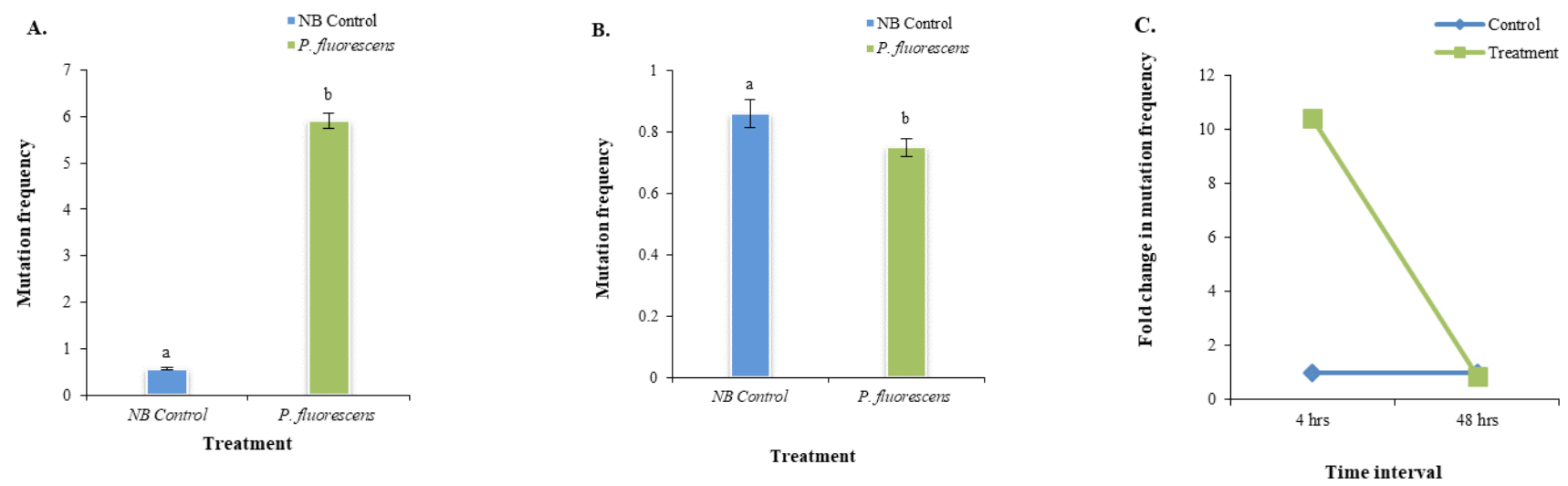

Fig. 7: A. Effect of $P$. fluorescens on SHR in control (treated with nutrient broth devoid of bacteria) and infected plants at 4 hours, B. Effect of $P$. fluorescens on SHR in control and infected plants at 48 hours, $\mathbf{C}$. Temporal influence of $P$. fluorescens on host SHR rates. Bars indicate the standard error of the mean of three biological repeats, each consisting of around 100 plants. ${ }^{a, b}$ represent that different letters stand for significant difference at $1 \%$ and $5 \%$ level respectively as determined by Student's t-test.
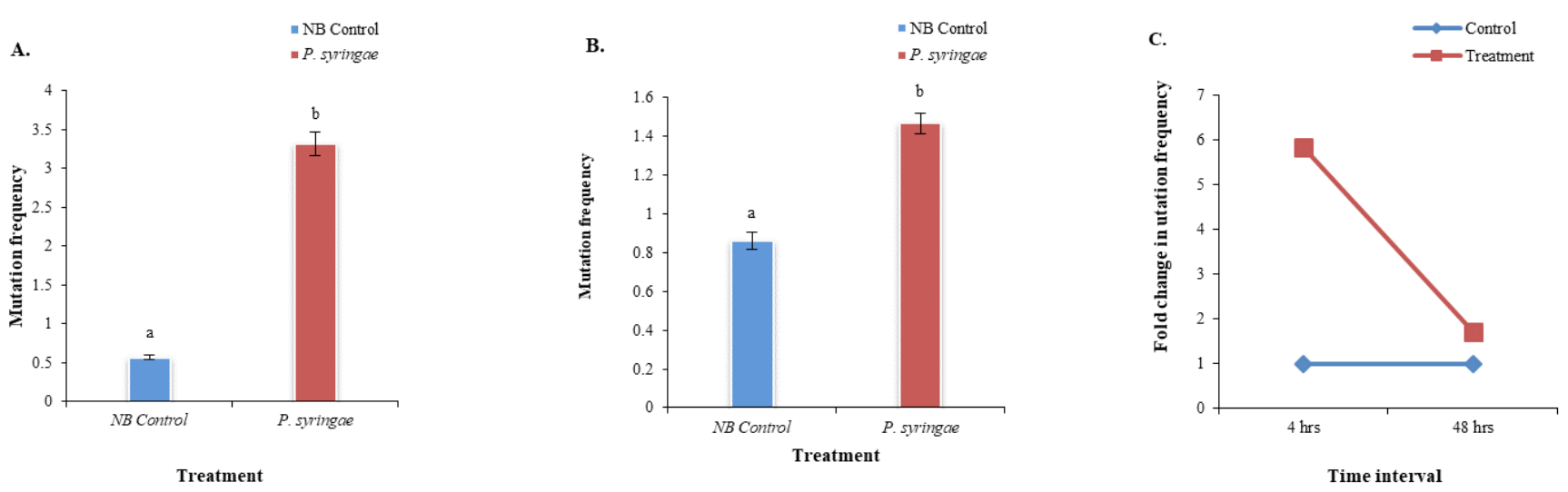

Fig. 8: A. Effect of P. syringae on SHR in control (treated with nutrient broth devoid of bacteria) and infected plants at 4 hours, B. Effect of $P$. syringae on SHR in control and infected plants at 48 hours, C. Temporal influence of $P$. syringae on host SHR rates. Bars indicate the standard error of the mean of three biological repeats, each consisting of around 100 plants. ${ }^{a, b}$ represent that different letters stand for significant difference at $5 \%$ level as determined by Student's t-test.

It has been previously reported that infection with Agrobacterium tumefaciens strain devoid of vir genes did not alter FSM and SHR rates and those with vir genes suppressed FSM and SHR rates (Shah et al., 2015). In contrast, $R$. leguminosarum, though closely related to $A$. tumefaciens, gave a result clearly distinct from that induced by the latter. A suppression of SHR was shown by R. leguminosarum but that was short-lived which lasted for at least 4 hours (Table 3). Pathogens like Tobacco mosaic virus and Oilseed rape mosaic virus were previously found to be inducers of SHR (Kathiria et al., 2010; Kovalchuk et al., 2013). The pathogenic $P$. syringae also led to enhanced FSM and SHR (Table 3). Unlike the above two bacteria, the effect observed in the case of $P$. fluorescens infection was a suppression of SHR frequency although the first-hand response was an initial induction of SHR (Table 3). Our work indicates that stress exposure duration plays an important role as the dynamics of SHR and FSM rates induced by the three bacteria were distinct (Table 3 ). For example infection period did not seem to influence FSM rates while SHR rates increased due to $R$. leguminosarum. In contrast, FSM rates increased and SHR rates decreased with increase in infection time upon infection with $P$. syringae.

Previously infection studies of Arabidopsis with $P$. syringae revealed that the plant's defence mechanisms do help to suppress

Table 3: Host somatic mutations in response to various soil bacteria.

\begin{tabular}{|c|c|c|c|c|}
\hline Mutation type & Time & Rhizobium leguminosarum & Pseudomonas syringae & Pseudomonas fluorescens \\
\hline \multirow[t]{3}{*}{ Frame-shift mutation } & 4 hours & $\uparrow$ & $\uparrow$ & $\downarrow$ \\
\hline & 48 hours & $\uparrow$ & $\uparrow$ & $\downarrow$ \\
\hline & Trend & $\square$ & $\nearrow$ & $\searrow$ \\
\hline \multirow[t]{3}{*}{ Homologous recombination } & 4 hours & $\downarrow$ & $\uparrow$ & $\uparrow$ \\
\hline & 48 hours & $\uparrow$ & $\uparrow$ & $\downarrow$ \\
\hline & Trend & $r$ & $\searrow$ & $\searrow$ \\
\hline
\end{tabular}

Note: The up and down arrows indicate increased and suppressed mutation rates in comparison with controls. The slant arrows $\lambda$ and $\searrow$ indicate gradual increase or suppression of mutation rates with respect to infection duration. The symbol $\square$ indicates no change in the trend of mutation rates due to infection time. 
DNA damage caused by pathogen attack (Song and Bent, 2014). The internal response pathways induced by the three bacterial strains are different. For example, P. fluorescens, the PGPR, is known to stimulate induced systemic resistance (ISR) while $P$. syringae, the pathogen is known to activate the systemic acquired resistance (SAR) (Cui et al., 2005; Sahu et al., 2018). Rhizobium is known to suppress plant immunity (Gourion et al., 2015). The mechanisms of SAR and ISR have distinct signalling pathways involving different biomolecules. Though this adds on the explanation for the mutation-suppressive nature of $P$. fluorescens, it has opened window for more research. Such a mutation-suppressing property of $P$. fluorescens is a desirable feature as it offers more stability of the genotype, thus ensuring consistent transfer of desirable traits in agronomically important crops.

\section{Conclusions}

R. leguminosarum induced spontaneous FSM in plants irrespective of the infection period. $P$. syringae lead to a temporal increase of FSM. In contrast, $P$. fluorescens lead to a temporal suppression of FSM in plants. R. leguminosarum suppressed SHR in plants initially at $4 \mathrm{~h}$ post infection, but a significant increase was observed $48 \mathrm{~h}$ post-infection. $P$. syringae induced SHR which though gradually decreased with the increase in co-cultivation duration, was still higher than the controls. P. fluorescens stimulated a short-lived SHR $4 \mathrm{~h}$ post-infection, while the mutation rate reduced $48 \mathrm{~h}$ post infection i.e. suppression of SHR was obtained.

\section{References}

Azaiez, A., Bouchard, E.F., Jean, M. and Belzile, F.J. 2006. Length, orientation and plant host influence the mutation frequency in microsatellites. Genome 49: 1366-1373.

Bashan, Y. and de-Bashan, L.E. 2010. How the plant growth promoting bacterium Azospirillum promotes plant growth-a critical assessment. Advances in Agronomy 108: 77-139.

Cui, J., Bahrami, A.K., Pringle, E.G., Hernandez-Guzman, G., Bender, C.L., Pierce, N.E. and Ausubel, F.M. 2005. Pseudomonas syringae manipulates systemic plant defences against pathogens and herbivores. Proceedings of the National Academy of Sciences of the United States of America 102(5): 1791-1796.

Gourion, B., Berrabah. F., Ratet, P. and Stacey, G. 2015. Rhizobium-legume symbioses: the crucial role of plant immunity. Trends in Plant Science 20(3): 186-194.

Hauser, M.T., Aufsatz, W., Jonak, C. and Luschnig, C. 2011. Transgenerational epigenetic inheritance in plants. Biochimicaet Biophysica Acta 1809: 459-468.

Hohn, B., Zipfel, C., Ries, G. and Molinier, J. 2006. Transgeneration memory of stress in plants. Nature 442: 1046-1049.
Jefferson, R.A. 1989. The GUS, reporter gene system. Nature 342: 837-838. Kathiria, P., Sidler, C., Golubov, A., Kalischuk, M., Kawchuk, L.M. and Kovalchuk, I. 2010. Tobacco mosaic virus infection results in an increase in recombination frequency and resistance to viral, bacterial and fungal pathogens in the progeny of infected tobacco plants. Plant Physiology 153(4): 1859-1870.

Kovalchuk, I., Hohn, B. and Kovalchuk, O. 2000. Genome wide variation of the somatic mutation frequency in transgenic plants. The EMBO Journal 19(17): 4431-4438.

Kovalchuk, I., Boyko, A., Hudson, D., Bhomkar, P. and Kathiria, P. 2006 Increase of homologous recombination frequency in vascular tissue of Arabidopsis plants exposed to salt stress. Plant and Cell Physiology 47(6): 736-742.

Kovalchuk, I., Kathiria, P. and Yao, Y. 2013. A systemic increase in recombination frequency upon local infection of Arabidopsis thaliana plants with oilseed rape mosaic virus depends on plants age, initial inoculum concentration and the time for virus replication. Frontiers in Plant Science 4: 61.

Kranner, I., Minibayeva, F.V., Beckett, R. and Seal, C. 2010. What is stress? Concepts, definitions and applications in seed science. New Phytologists 188(3): 655-673.

Lucht, J.M., Mauch-Mani, B., Steiner, H.Y., Metraux, J.P., Ryals, J. and Hohn, B. 2002. Pathogen stress increases somatic recombination frequency in Arabidopsis. Nature Genetics 30(3): 311-314.

Lugtenberg, B. and Kamilova, F. 2009. Plant growth promoting rhizobacteria. Annual Review of Microbiology 63: 541-556.

Puchta, H., Swoboda, P., Gal, S. and Hohn, B. 1994. Induction of intrachromosomal homologous recombination in whole plants. The EMBO Journal 13(2): 484-489.

Rahavi, M.R., Kovalchuk, I., Migicovsky, Z. and Titor, V. 2011. Transgenerational adaptation to heavy metal salts in Arabidopsis. Frontiers in Plant Science 2: 91

Sahu, B., Singh, J., Shankar, G. and Pradhan, A. 2018. Pseudomonas fluorescens PGPR bacteria as well as biocontrol agent: A review. International Journal of Chemical Studies 6(2): 01-07.

Shah, J.M., Ramakrishnan, A.M., Singh, A.K., Ramachandran, S., Unniyampurath, U., Jayshankar, A., Balasundaram, N., Dhanapal, S., Hyde, G. and Baskar, R. 2015. Suppression of different classes of somatic mutations in Arabidopsis by vir gene-expressing Agrobacterium strains. BMC Plant Biology 15: 210.

Song, J. and Bent, A.F. 2014. Microbial pathogens trigger host DNA doublestrand breaks whose abundance is reduced by plant defense responses. Public Library of Science Pathogen 10(4): e1004030.

Tuba, Z. and Lichtenthaler, H.K. 2007. Long-term acclimation of plants to elevated $\mathrm{CO}_{2}$ and its interaction with stresses. Annals of New York Academy of Sciences 1113: 135-146.

Yao, Y. and Kovalchuk, I. 2011. Abiotic stress leads to somatic and heritable changes in homologous recombination frequency, point mutation frequency and microsatellite stability in Arabidopsis plants. Mutation research/Fundamental and Molecular Mechanism of Mutagenesis 707(1-2): 61-66. 